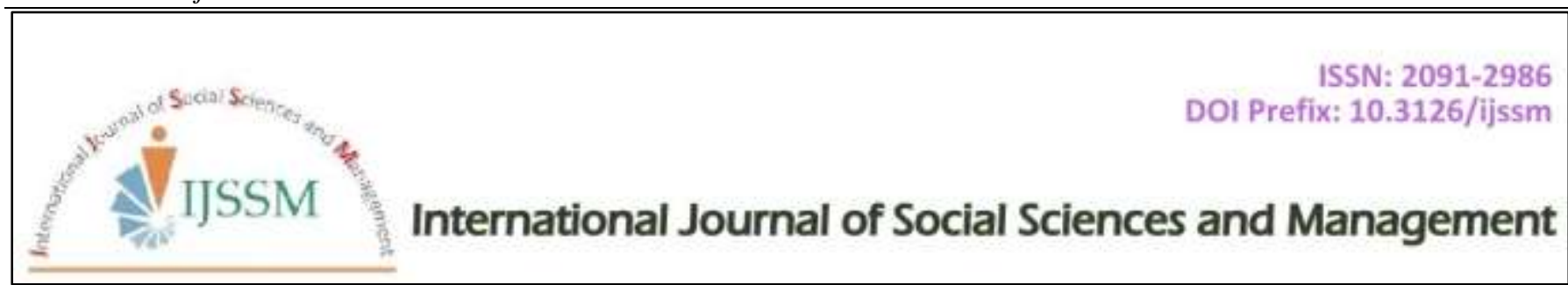

Research Article

\title{
To Identify the Causes of Stress among Nurses Working in Intensive Care Unit of Ittefaq Hospital Lahore
}

\author{
Salma Johan, Hajra Sarwar* and Iram Majeed \\ Lahore School of Nursing (LSN), The University of Lahore, Pakistan \\ *Corresponding author's email: hajirasarwer@gmail.com
}

\begin{abstract}
The study is aimed at identifying the causes of stress amongst daily routine of nurses working in the ICU unit of Ittefaq Hospital Lahore. A questionnaire was developed and distributed to gain an insight into factors which may be causing stress to the nurses. The results were analyzed using statistical tools. An overall finding of the study is that all the nurses were suffering from stress however, the reasons of stress are different. Consensus was that three biggest causes of stress are prolonged shifts and extra duties, shortage of staff and excessive workload.

The other major causes of stress identified are inappropriate or poor communication between doctors and nurses, lack of support and motivation, unexpected deaths or patients undergoing painful procedures, lack of breaks, lack of cooperation from peers and supervisors/managers. The patients themselves can also be a source of stress for example, problematic patients or their aggressive family members as well as improper work environment also contribute to stress.

There is a dire need to develop stress alleviating programs and therapies at the hospitals. Nurses, doctors and managers should be encouraged to participate in such programs towards building stress-free work environment where patients can be served better.
\end{abstract}

Keywords: Nurses; Stress; Intensive care unit; work overload; prolonged shifts; problematic patients; aggressive family members; lack of communication

\section{Introduction}

Stress can be defined as the internal response to external events. In other words stress is what the body and mind experience when we try to adopt a continually changing environment. The challenge of work becomes more complex and due to this the meeting ability of the individual is disturbed. Work place stress has long been recognized as a challenge for the nursing profession. Nursing is a profession of high stress which affects physical as well as mental health of the nurses. There are a lot of reasons due to which stress is caused in nurses. On the other hand work related stress can be positive because it can help to prepare the nurses for life's challenges, but if pressure and demand exceed then it leads to work related stress. A stressor is anything that causes the release of stress hormones. There are two broad categories of stressors: Physiological stressors and Psychological Stressors. Different kinds of stressors in nurse are work load, shortage of staff, lack of support from supervisors, conflict with peers and doctors, demanding patients and relatives (Khan \& Sayed, 2015).

\section{Background}

Stress is everyday life's reality. Everyone is struck by it in one way or the other. No one is safe from it and no one can avoid it, because we are living in an unpredictable world. Everyone faces stress in different life situations and circumstances, which make them physically and emotionally overwhelmed and vulnerable. Stress creates either a positive or a negative effect on life. Positive stress is motivating and leads to progress, new inventions and awareness. On the contrary, negative stress develops feeling of distress, rejection, depression and leads to physical and mental problems or trauma.

According to Klinic community health, (2010) we may be motivated by events of our lives or we may respond to some stressful events in the manner that have negative effects on our physical, mental and social well-being. 
In a hospital setting, intensive care units (ICUs) are very important. In these units, critical and unstable patients are being treated. Patients are put on artificial ventilators, oxygen, hemodialysis machines, Bypass and other equipment which are necessary for patients' survival. These patients require specialized care, medical and nursing. These patients are not stable and their condition may change within minutes or even seconds. Nurses are supposed to be very vigilant, cautious and active there as every second counts. They are expected for continuous monitoring and support to the other medical staff and above all the patients.

Nurses working in intensive care units should be very skillful, efficient, and active with complete knowledge of the medical equipment so that any technical or technological challenge can be handled well at appropriate time. They should have specialized knowledge and training, to provide high quality care to the patients. Nurses face a lot of stress while working in such a high pressure environment. Stress may be due to working environment, work overload, shortage of staff, or conflicts with physicians or co-workers and pressure from family members. Life and death situations, prolonged duty hours are other factors contributing to the work related stress.

The existing nurse to patient ratio is approximately 1:50 whereas PNC's prescribed ratio is 1:10 in general areas and 2:1 in specialized areas (Chauhan, 2014). In United States nurse to patient ratio in general ward is $1: 5$ and in special care units is 1:1 (McDonagh, 2014).

I worked in intensive care unit of Ittefaq Hospital for couple of years. Many times we face same situations when family members become very aggressive and abusive. They just started shouting on us because according to them they were paying for everything. Sometimes they are not satisfied with doctors as patient's condition is not improving or becoming worse in spite of all the efforts. They become frustrated and annoyed. We also face shortage of staff and high workload as well. When new nurses or staff are appointed to our unit they need time to learn new skills and knowledge to handle special equipment. They often make mistakes while performing procedures like ABGs sampling or operating an equipment. Moreover, sudden collapse of patient, putting patient on a ventilator or death of patient add to the stress of an already stressful work environment. Many times work related conflicts with doctors and among nurses also make environment tense and uncomfortable for working.

Stress in nurses has been a hot topic of research and various studies have been conducted to document the factors causing stress amongst nurses over the years. We can also see what other authors had said about it.

According to McGrath, many of the stresses identified amongst nurses concerned working relationship with nurse and doctor and other healthcare staff, communication and relationship with patient and relatives, high level of knowledge and skills required, the necessity to respond immediately in emergency situation, very high work overload and understaffing, lack of support and lack of break time during duty hours.(McGrath et al., 2003)

In a nutshell, we can say nursing occupation is subject of high level of stress. The practice of nursing profession mostly occurs in hospital environment. It is very demanding profession as more care and attention is required for patients. It is the question of health and patients are away from their family members and have least or no information as to what is going to happen. These things cause emotional stress to patients. They start relying more on nurses for care, comfort and proper attention for recovery, which in turn increases the stress on nurses. A nurse provides necessary information regarding their disease and problem. Nurse remains with patients all the day and night to provide assistance.

Nurses remain in contact with the patient suffering from pain, depression, hopelessness, grief, and life and death situation throughout their stay in the hospital. (Cavalheiro et al., 2008)

\section{Significance of the study}

The aim of study is to identify the causes of stress in nurses working in intensive care unit, to find out least perceived source of stress. By this study, nurses will be able to select the coping strategies while working in intensive care unit. These strategies could be social support therapy, emotional support therapy and relaxation therapy (.e.g., deep breathing exercise; be calm, polite and confident). Learn to handle inner conflict with nurses and doctor by using problem solving strategies.

Negative stress can be minimized by using stress education and managerial strategies and improved workplace environment.(Mehta \& Chaudhary, 2005)

Deep breathing releases tension from the body and clears the mind, improving both physical and mental wellness. (Centre, 2010)

\section{Justification of the topic}

I chose this topic because I worked in intensive care unit for more than four years. We also faced similar stress causing situations as mentioned above e.g., work overload, aggression of patients' family members, shortage of staff and lack of support from seniors. Patients are ignored due to shortage of staff and over burden. Nurses have uncooperative behaviour with each other. We felt depression and rejection when our seniors did not appreciate us for doing good job. Therefore, I can closely relate to the topic and have firsthand knowledge of the various stress causing factors. I think by approaching this important topic in a scientific manner I can add to the better understanding of the topic and make a positive contribution. 
Most of researchers are done in tertiary care hospital, I want to cheek stress level in private sector.

\section{Purpose of the study}

The main objective of this study is to determine cause of stress among nurses who are working in the intensive care units. To identify work-related stress and other factors related to it, and method to handle it.

\section{Research Questions}

1. Lack of knowledge about operating special equipment (ventilators, monitors, defoliators) in intensive care units cause stress.

2. Work over load cause stress.

\section{Hypothesis}

\section{Alternative hypothesis}

Nurses who are working in intensive care unit of Ittefaq hospital may have stress.

\section{Null hypothesis}

Nurses who are working in intensive care unit of Ittefaq hospital may not have stress.

\section{Objective}

The objective for this research is to determine the causes of stress among nurses of Ittefaq hospital Lahore.

\section{Conceptual Definition}

Stress

Stress is defined as pressure or worry caused by problems in someone's life. Things can go wrong when people are under stress. (Oxford dictionary, 2015)

\section{Intensive care unit}

Intensive care unit is a ward having limited numbers of beds where seriously ill patients are kept. Extra specialized treatment, nursing care and other facilities are made available which are not available in general ward. It provides medical and surgical care to critical patients like cardiac patients, cerebrovascular accident cases and major surgery cases. (Gupta, 2004)

\section{Nurse}

She is trained to look after those who need medical and nursing care either in hospital or at home. Some are super specialists who have trained in special branches i.e. heart, dental and Operation Theater and intensive care units. (Gupta, 2004)

\section{Violence in work place}

Work place violence means threatening behaviour, conflicts in working relation, verbal abuse and physical attacks like pushing or kicking.

\section{Work over load}

Too much work and the work that is too difficult to be done with particular resources over a given period.
Shortage of nursing staff

The limited number of available nurses is burdened with all the workload eventually affecting the quality of service provided.

\section{Operational Definitions}

Stress

Stress occurs when person is not able to cope with environmental pressure and it exceeds his/her resources to overcome.

Nurse

Nurse is a person who is trained and educated to look after sick and ill patients either in home, hospitals or in community center. Some are trained in special units like cardiac care units, intensive care units and operation theaters.

\section{Intensive care unit}

These are units for very sick and serious patients are being kept for close monitoring, and observation. In these units patients are put on artificial ventilator and pacemaker according to patient's condition. Special nursing care and medical care is being provided.

\section{Work load}

Work over load means when someone has to do too much work in limited period of time.

\section{Work place violence}

Work place violence means aggressive behaviour in the work place by colleagues, physicians, patients and family members.

\section{Shortage of staff}

It is defined as whennumber of nursing staff is limited and is not according to the PNC standard which is $1: 10$ in general ward and special units 1:2. But in Pakistan we have 1:50 ratio. It leads to shortage of staff.

\section{Literature Review}

Stress in nursing profession is an ongoing problem worldwide. Nurses face high level of stress in health care centres. They are facing patients, their relatives, families, communities to provide high quality care at the same time. Environmental factors also contribute a lot in work place stress.

According to Khamisa stressors contributing to the experience of work related stress, include poor supervision, conflicts with peers and patients, high job demands and overtime are all associated with one or more dimension which leads to stress.(Khamisa, Oldenburg, Peltzer, \& Ilic, 2015)

French, et, al. identified nine scales of work place stressors that may have impact on nurses; conflict with the physician, inadequate preparation, problems with peers, problems with supervisor, discrimination, workload, uncertainly 
concerning treatment, dealing with death and dying patients, patients and their families.(French, Lenton, Walters, \& Eyles, 2000)

In clinical practice, nursing professionals are often faced with difficult and emotionally charged situations, such as the prolonged suffering and death of a patient, generating feelings of sadness, anxiety, frustration, helplessness and even guilt as mentioned by Martins, Chaves, \& Campos, 2014.

Stress is important for nurses and any other person to improve the work performance and solve the problems efficiently but too much of stress has usually negative effects and reduces the work performance while increasing the chances of becoming ill or sick at the same time.

Ramezanli et al. state that nurses' occupational environment is filled with various forms of stress, which can have negative consequences not only for their physical and mental health, but their performance and their organizations' productivity. (Ramezanli et al., 2015\}.

Zakerian describes that workload is most important stressor amongst the nurses working in hospital and as a result it increases stress level and decreases productivity of nurses.(Zakerian, 2014)

Nizamiet, al states that sources of stress in nurses are clinical workload, difficulty in relationships, and poor recognition of hard work, non conducive organizational climate, immense personal responsibility, managerial role difficulties.(Nizami et al., 2006).

People become sick and they need hospital admission and require special attention from nurses for good and speedy recovery. They depend on nurses for treatment and nursing care. This is due to workload and specificity of the task that they have to deal with deaths, emergency situation, control of material used and equipment; meet the demands of family members, performance of activities within limited timeframe, noise from the machines, suffering and anguish of family members.

Milutinovic states that nurses in daily life are exposed to life and death situation, excessive workload, long work hours in different shift, competition, insufficient knowledge and information sharing with peers or physicians. They are working in different environment and facing more stress as compared to other health care professionals.(Milutinović et al., 2012)

Ugur et al. (2007) describes that nurses are working in unique environment that is full of noise pollution and susceptibility of infection. It is a job that needs patience and mental and physical capabilities.

According to Shila, ICU stressors include working relationship with other nurses and health care workers, communication and conversation with the patient, high level of knowledge and skills needed to work in this ward, high workload, need to respond quickly and promptly to urgent situations and heavy responsibility caused by patient care. Heavy workload, low support from administrators, nurses' lack of control over work environment, low teamwork and conflict are the most important stressors.(Shila Latifzadeh, 2015)

\section{Theoretical Framework}

Stress was first defined by Hans Selyes, (1907- 1982), a Hungarian endocrinologist. He gave a scientific explanation for biological stress and introduced general adaptive syndrome (GAS) theory.

After GAS theory, various theories and frameworks have been introduced to handle and cope with stress. One of them is Transactional Model of Stress and Coping. It is a framework for evaluating the processes of coping with stressful events and situations. According to this model stress is related to external environment and it shows its relation to individual cognitive process and emotional response of the individual. By this theory coping behaviour is defined as constantly changing cognitive and behavioural efforts to manage specific internal and external demands. This model has five stages.

\section{Stage one}

Origin of the demands and its direct relation with person and with its environment.

\section{Stage two}

The person's perception of demands and its ability to cope, because stress is result of imbalance with person's ability to cope.

\section{Stage three}

Response of the person to the demand. This stage is usually stressful as the result of demands.

\section{Stage four}

The coping action and response delivered by person.

Stage five

The final stage the feedback and feed forward.

These five stages not only define the stress process but also set the foundation for further discussion to cope with the situation. This theory can be used to manage stress in nurses. This theory postulates that coping behavior affects well-being and adaptation; In addition, coping behavior has also received attention from nursing researchers. (Kato, 2014)

\section{Material and Methods}

\section{Instrument and Apparatus}

For this study, questionnaire was distributed among nurses of intensive care unit. Data was analysed on SPSS. Laptop and internet was used. Validity was checked by pilot study. Power point presentation on relaxation technique was made. 


\section{Procedure}

It is a cross sectional descriptive study, convenient sampling technique was used. Questionnaire was distributed among nurses of intensive care units according to inclusive criteria. Questionnaire wasto be filled by them.

\section{Target population}

This study was conducted on nurses working in intensive care units of Ittefaq Hospital Lahore.

\section{Inclusion Criteria}

All staff nurses who are working in intensive care units.

\section{Exclusive criteria}

Trainee and student nurses are not involved.

Nurses who refused to give consent for the research study.

\section{Sample size}

Sample size is 92 according to slovin's formula (Ellen, 2012):

$$
n=\frac{N}{1+N(E) 2}
$$

Total population $=120$

95\% confidence

$5 \%$ error $5 / 100=0.05$

If $\mathrm{N}=120 \mathrm{n}=$ sample size

$\mathrm{E}=$ margin of error

$\mathrm{n}=\mathrm{N} /\left[1+(\mathrm{N})(\mathrm{E})^{2}\right]$

$\mathrm{n}=120 /\left[1+120(0.05)^{2}\right]$

$\mathrm{n}=120 /[1+120(0.0025)]$

$\mathrm{n}=120 /[1+0.3]$

$\mathrm{n}=120 / 1.3$

$\mathrm{n}=92$ (approx.)

\section{Sampling Technique}

Convenient sampling technique was used.

\section{Study Design}

Cross sectional descriptive study was used to achieve the objectives.

\section{Study Duration}

From April 13, 2015 to May 15, 2015 (approximately two months).

\section{Study Variable}

Dependent variable

Stress

Independent variable
Work over load; prolonged duties, lack of support from supervisor, conflict with doctors and peers, shortage of staff.

\section{Research Tools}

Data was collected by questionnaire. The tool was likert type with 5 points namely; strongly agree, agree, satisfied, disagree, and strongly disagree.

\section{Data Gathering Plan}

The entire questionnaires were distributed among nurses. Data was collected from them in one week. Any queries or doubts about questionnaire were answered promptly.

\section{Data Analysis}

Data was entered, and analyzed using the statistical package of the social sciences software (SPSS). Frequency and percentage was identified. Mean, Maiden, Mode relationship among different variables were calculated and graphically portrayed in tables and graphs.

\section{Ethical Considerations}

Participants were provided information regarding research and its nature in order to gain the full consents. Letter of consent was attached with each questionnaire. That stated the basis of research, duration of participating confidentially and benefits as well. Ethical consent was taken from Chief Operating Officer and Matron of Ittefaq hospital Lahore as well. There was no risk and hazard for participants. In addition permission letter of research from ethical review committee of the University of Lahore was also taken.

\section{Results}

\section{Data Analysis}

92 nurses of Ittefaq Hospital Lahore were selected for this research study. The study sample, consisted of 2 male and 90 female nurses. The age range of the nurses was from 20 45 years. Research data was collected and entered in SPSS software for analysis. The software helped calculated the variables and the results are graphically portrayed in tables.

\section{Gender}

According to Fig. 1, it is evident that 2 male and 90 female enrolled which means that $2.2 \%$ were male and $97.8 \%$ were female. The frequency of female nurses is higher than male in this research study.

Age

Fig. 2 shows ages of nurses in this study, which ranged from 20-45 years. 62 nurses or $67 \%$ of them was between $20-25$ years while 24 or $26 \%$ nurses had age from $26-30$. Only 3 or $3.3 \%$ nurses had age ranging from $30-40$ years. 


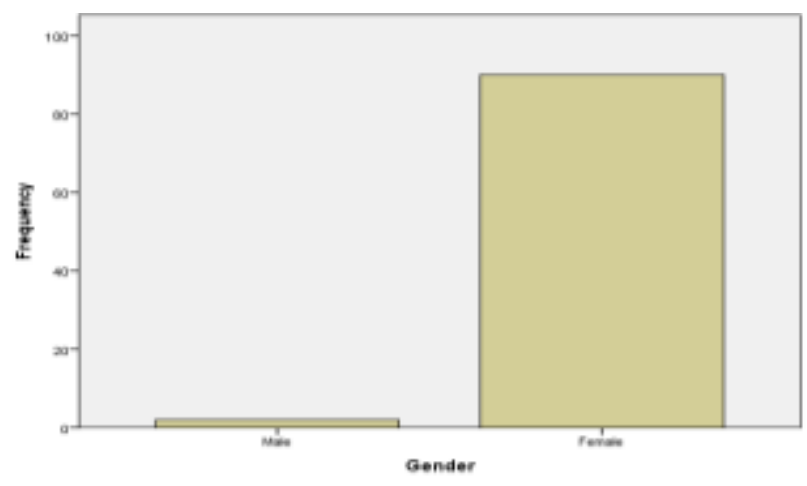

Fig. 1: Gender of the Study Participants

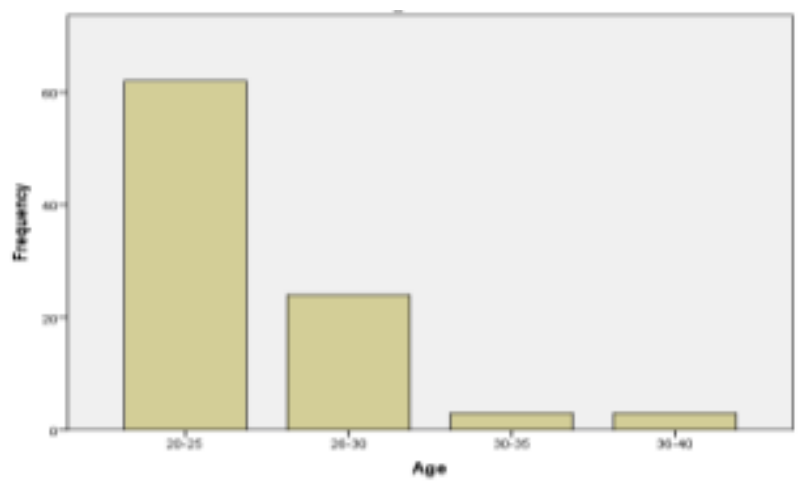

Fig. 2: Age of Study Participants

\section{Clinical Experience}

The overall experience of the nurses varied from 1 to 8 year(s). 54 nurses or approximately $58 \%$ of the total sample size has experience of 1-3 years while 31\% nurses had 4-6 years of experience. More experienced nurses were only $9 \%$, which have been working in Ittefaq for more than 8 years (Fig. 3).

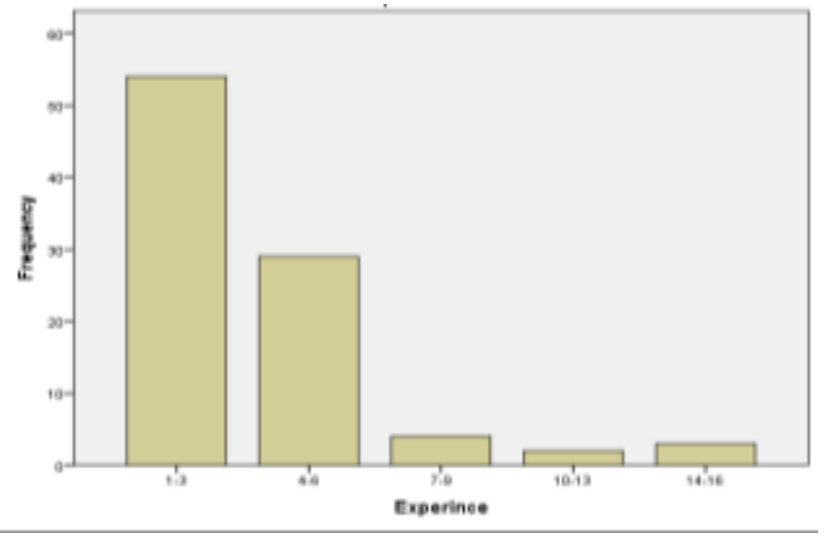

Fig. 3: Experience of Nurses

\section{Graphical Representation of Data}

In response to question 1,49 or $53 \%$ nurses strongly agreed that they lack proper knowledge and training to handle special equipment often used in the ICU which often causes stress amongst the nurses. 32 or $34.8 \%$ nurses agreed that lack of training causes stresses while $4.3 \%$ nurses were satisfied with the training they had was adequate while $7 \%$ disagreed lack of knowledge can cause stress. The data is presented in the Fig. 4.

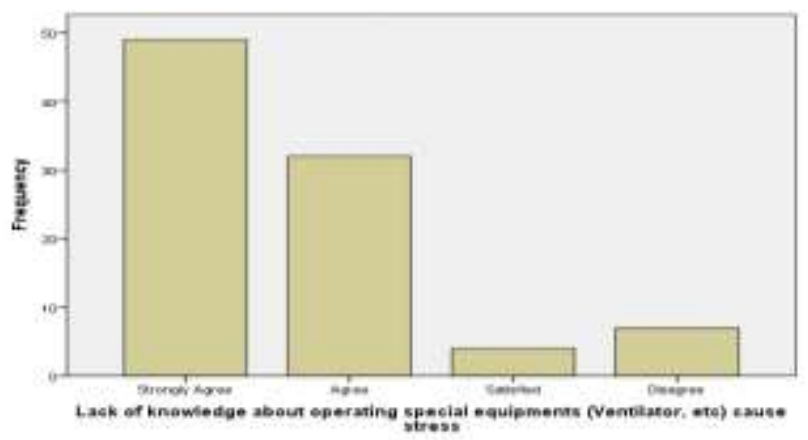

Fig. 4: Knowledge about equipment handling

For $2^{\text {nd }}$ question, $41(44.6 \%)$ of nurses strongly agreed that lack of practice and skills causes stress while $42 \%$ or 39 nurses agreed to the statement. $6.7 \%$ nurses were satisfied with the skills they had and disagreed that lack of practice can be a reason of stress amongst nurses as shown in the Fig. 5.

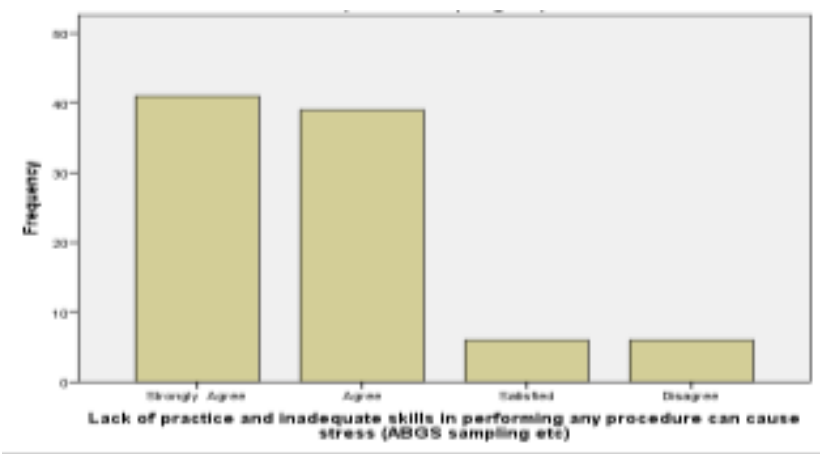

Fig 5: Lack of practice and skills causes stress

Fig. 6 summarizes the results of Question 3, which was related to excessive workload and stress. According to the data collected, 60 or $65 \%$ nurses strongly agreed and 29 or $31 \%$ agreed that excessive workload causes stress to them while only 3 or $3.3 \%$ nurses responded that workload does not cause them stress.

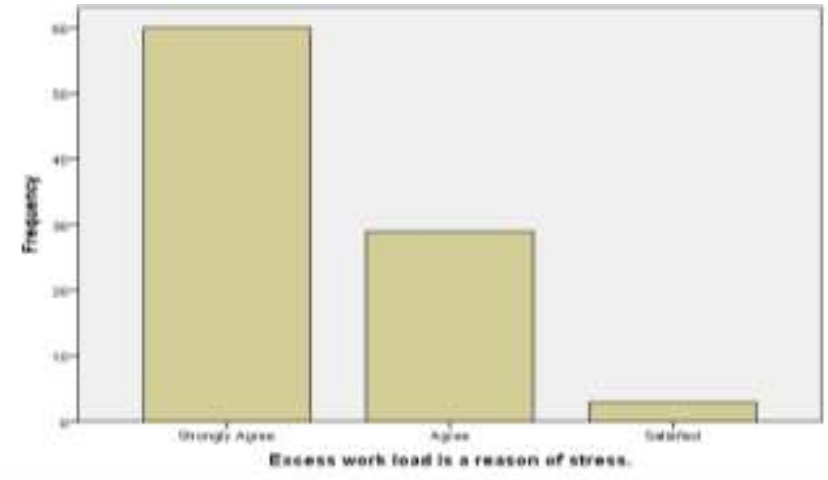

Fig 6: Effect of workload on the stress

In response to $4^{\text {th }}$ question, only 1 nurse responded that shortage of staff nurses does not cause stress whereas 59 or $64 \%$ were strongly agreed while 32 or $34 \%$ agreed that shortage of staff nurses cause stress as shown in Fig. 7. 


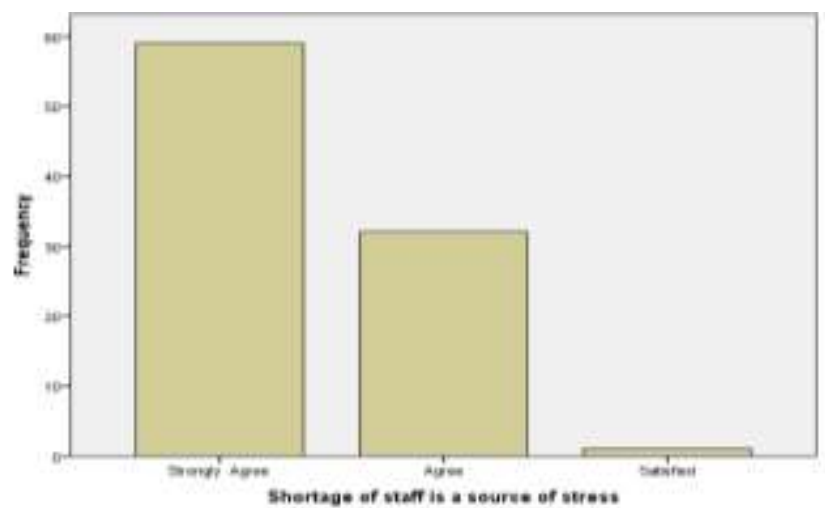

Fig. 7: Shortage of staff

For $5^{\text {th }}$ question about effect of prolonged shifts, $72(78 \%)$ nurses at Ittefaq Hospital strongly agreed that prolong shifts and extra shift causes stress and $12 \%$ agreed to the statement of the questionnaire. 3 or $3 \%$ disagreed and strongly disagreed each that this causes stress (Fig. 8).

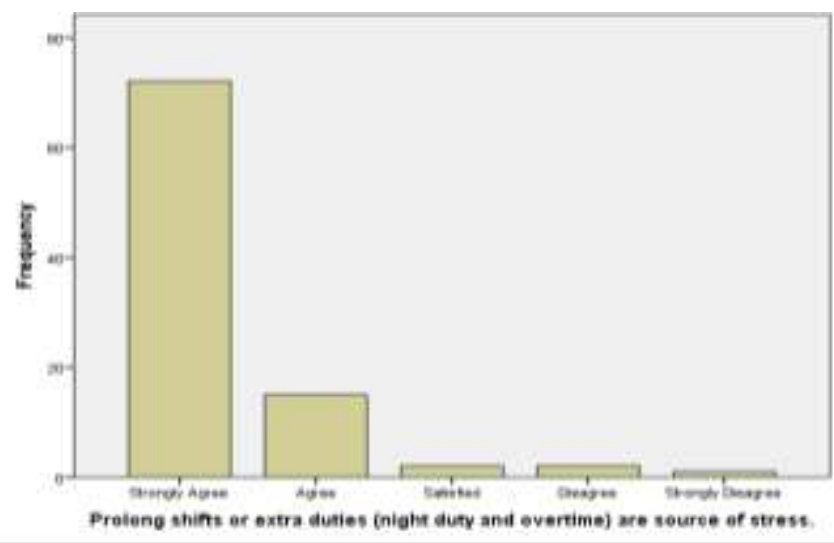

Fig. 8: Effect of prolonged shifts

In response to question 6,48 or $52 \%$ strongly agreed and 37 or $43 \%$ agreed that prolonged standing and lack of breaks causes stress. Only 4 or $4 \%$ were satisfied while 3 or 2 or 2.2 were disagree and strongly disagreed respectively as shown in Fig. 9.

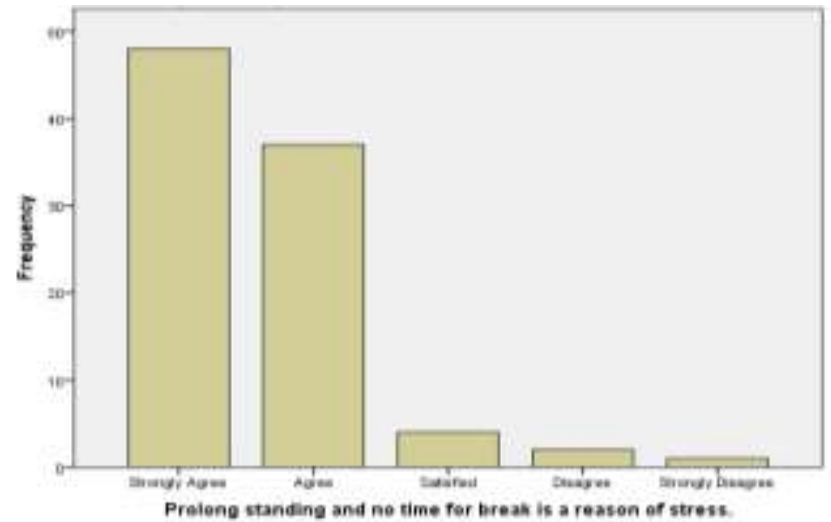

Fig. 9: Prolonged standing and lack of breaks

In response to question 7,63 or $68 \%$ nurses responded that they strongly agree and 24 or $26 \%$ nurses agreed that lack of support from supervisors/managers is a source of stress.
5 or $5.5 \%$ nurses disagree that lack of support from supervisor can cause stress as shown in Fig. 10.

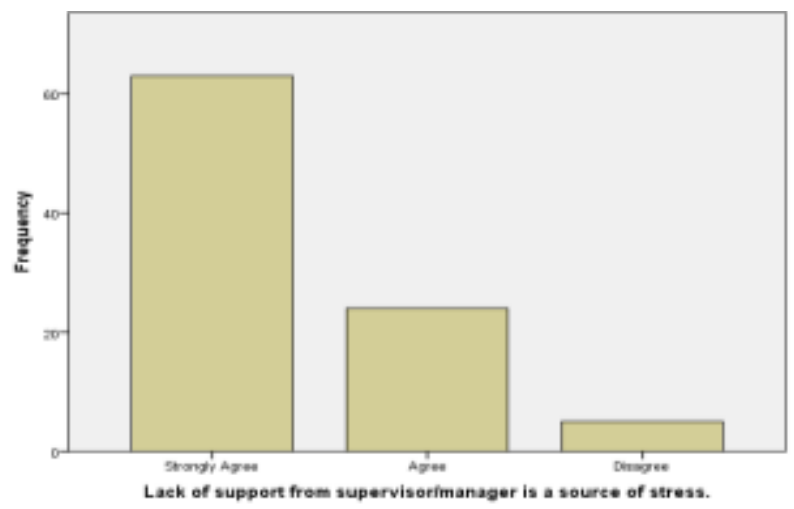

Fig. 10: Lack of support from supervisor/manager

In response to question 8 about lack of motivation and recognition, 47 or $51 \%$ of nurses strongly agreed and 40 or $43 \%$ agree that this lack causes stress. There were $4.3 \%$ nurses who were satisfied. The data is presented in Fig. 11.

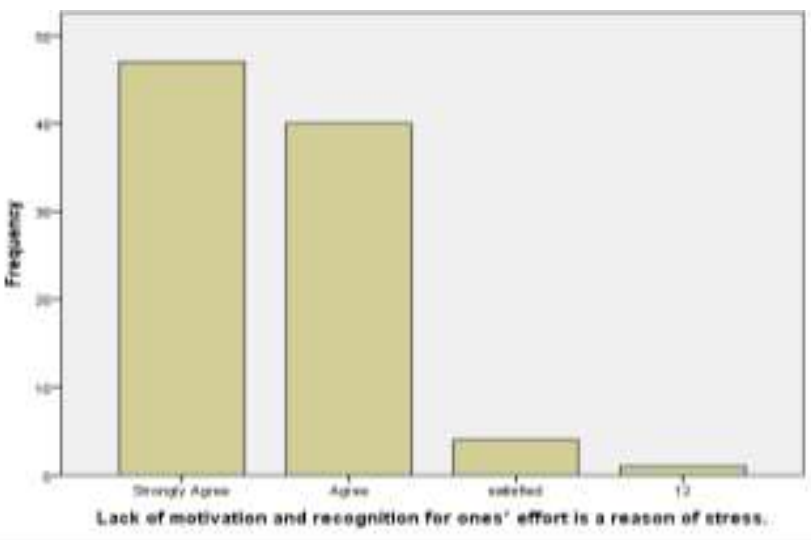

Fig. 11: Lack of motivation and recognition

In response question 9 about effect of conflicts during duty hour, 4 or $4.3 \%$ nurses strongly disagreed and 7 or $7.6 \%$ were satisfied with their work environment. 36 or $39 \%$ nurses strongly agreed and 44 or $47 \%$ agreed that such conflict cause stress to them (Fig. 12).

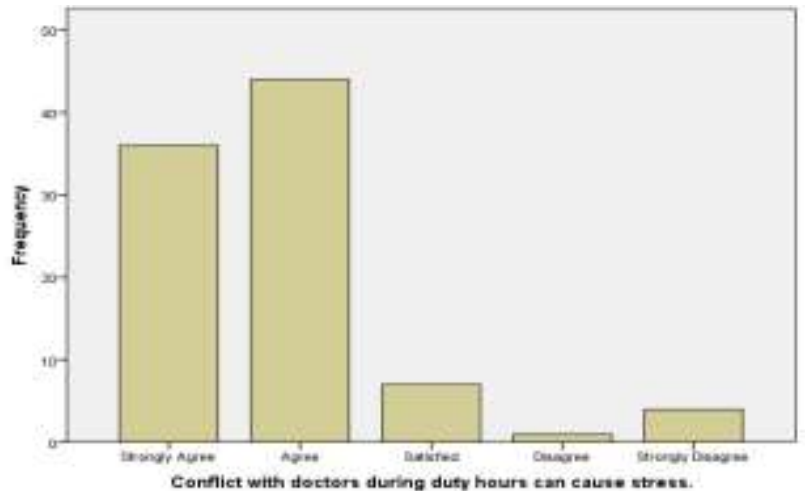

Fig. 12: Conflicts with doctors during duty hour causes stress

In response to question 10,46 or $50 \%$ nurses strongly agreed and 38 or $41 \%$ agreed that lack of cooperation is a 
cause of stress while 4 or $4.3 \%$ strongly disagree and $4.3 \%$ were satisfied as shown in Fig. 13.

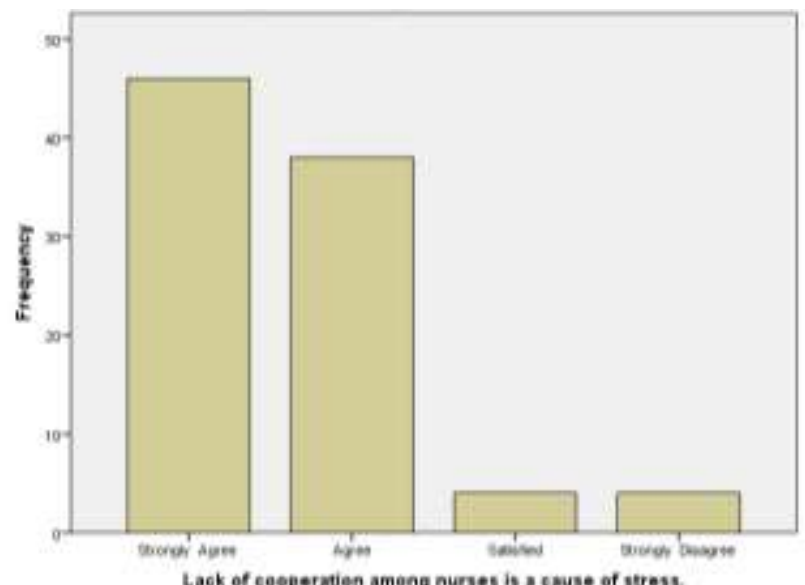

Fig. 13: Lack of cooperation amongst nurses causes stress.

In response to question 11,41 or $46.4 \%$ nurses strongly agreed 43 or $46.7 \%$ agreed that lack of resources can cause stress while 6 or $6.5 \%$ were satisfied and 1 or $1.1 \%$ disagreed as shown in the Fig. 14.

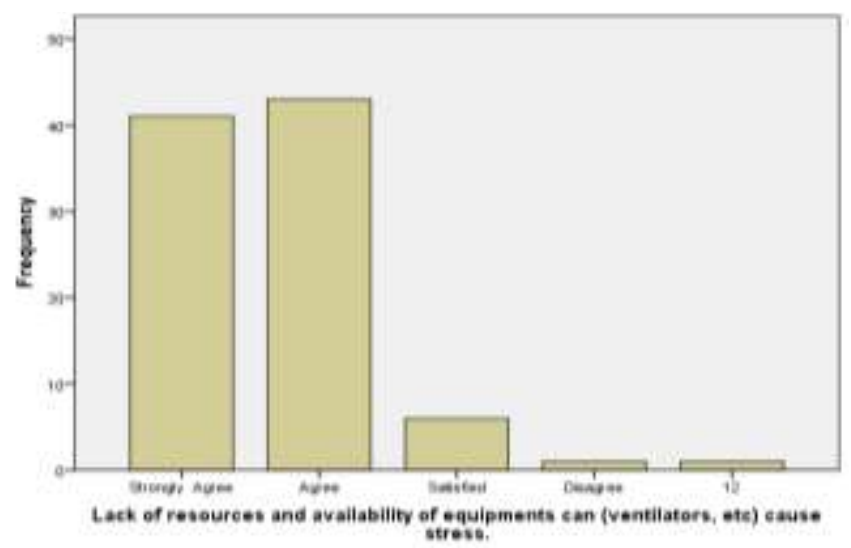

Fig. 14: Lack of resources causes stress

In response of question 12,52 or $56.5 \%$ nurses strongly agreed and 37 or $40.2 \%$ agreed that unexpected deaths of patients causes stress to them while 3 or $3.3 \%$ nurses were satisfied and said it did not causes them stress. The data is presented in Fig. 15.

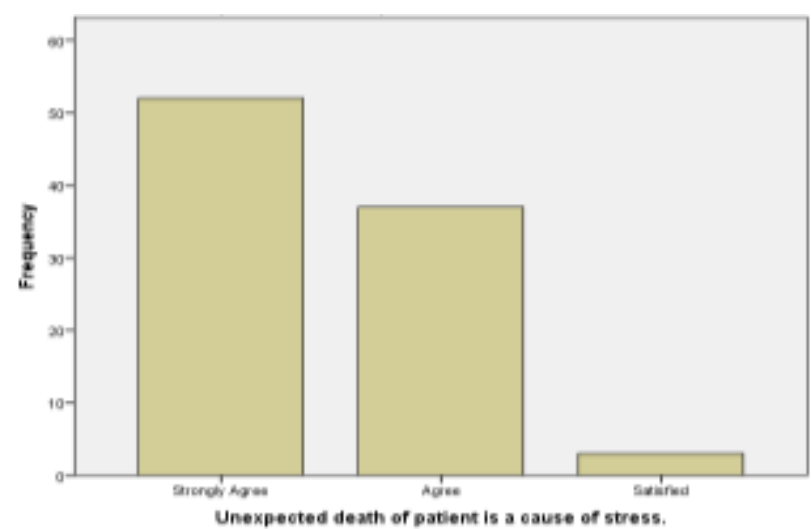

The response given by nurses of Ittefaq hospital to question 13 about problematic patients was that 46 or $50.0 \%$ strongly agreed and 40 or $43.5 \%$ agreed problematic patients or their misbehavior causes stress while 6 or $6.5 \%$ were satisfied. The data is shown in Fig. 16.

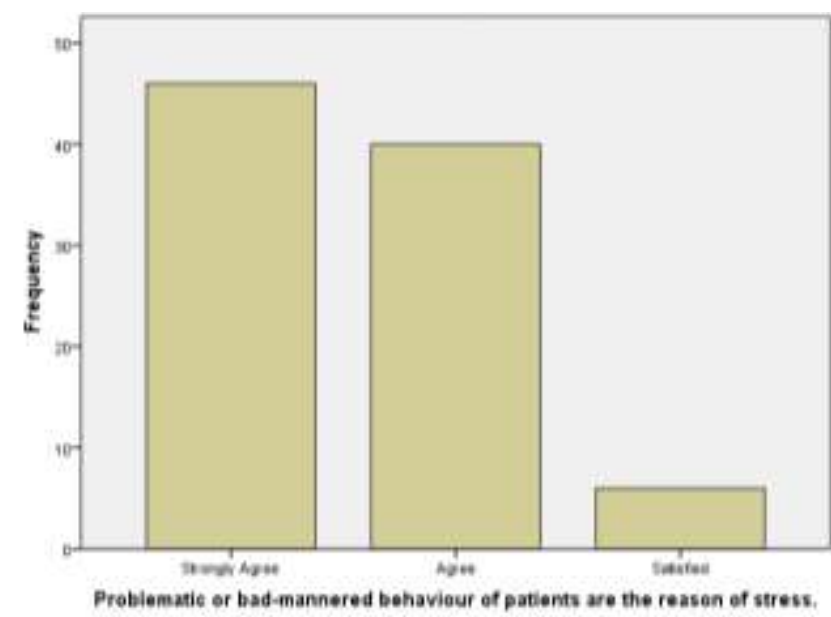

Fig. 16: Problematic patients cause stress

In response of question 14,40 or $43.5 \%$ strongly agreed and 44 or $47.8 \%$ agreed that aggressive and demanding family members are a source of stress. There were 3 or $3.3 \%$ nurse who were satisfied while 5 or $5.4 \%$ disagreed that aggressive and demanding family members are source of stress. The data is presented in Fig. 17.

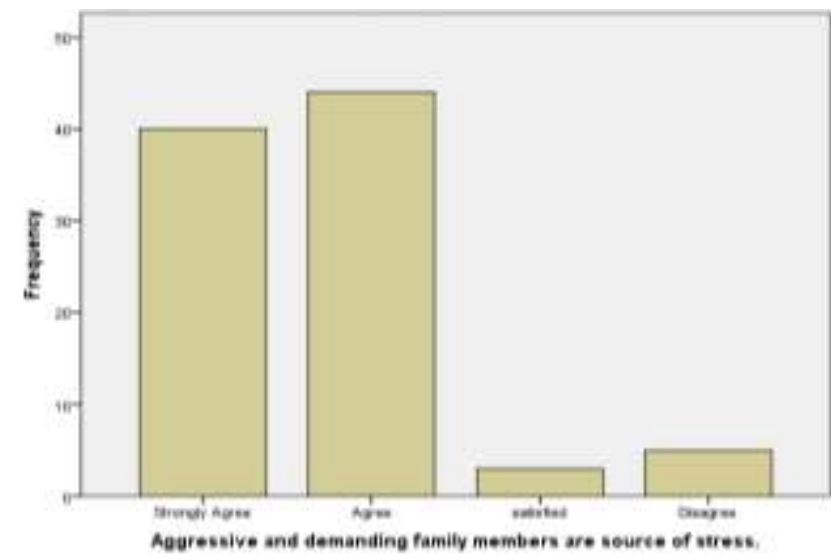

Fig. 17: Aggressive and demanding family members cause stress

In response to question 15,35 or $38 \%$ nurses strongly agreed and 49 or 53 . \% agreed that patients undergoing painful procedures causes them stress. There were 6 or $6.5 \%$ who were satisfied $1 \%$ disagreed that patient undergoing to painful procedure can cause stress to them as shown in Fig. 18.

Fig. 15: Unexpected death of patients causes stress 


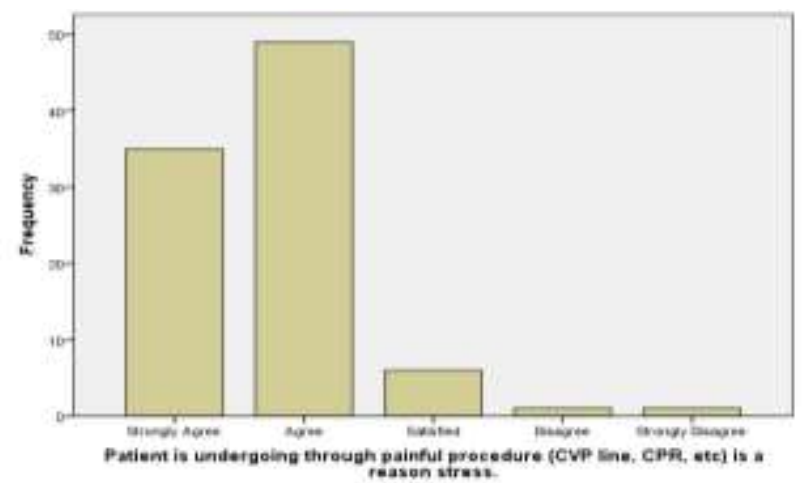

Fig. 18: Patient undergoing painful procedures causes stress

In response to question that fear of getting infection from patients can cause stress, 53 or $57.6 \%$ strongly agreed and 30 or $32.6 \%$ agree whereas 8 or $8.7 \%$ nurses were satisfied and only $1 \%$ strongly disagreed that it can cause stress to nurses (Fig. 19).

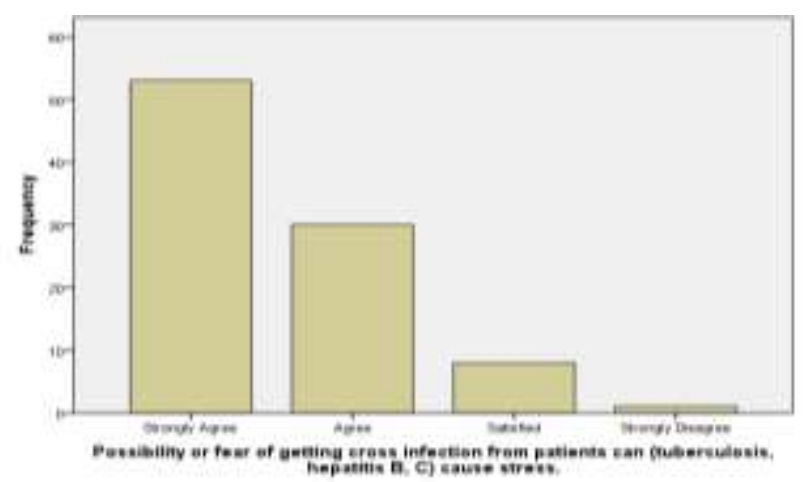

Fig. 19: Possibility of fear of cross infection from patients

In response to question 17,48 or $52.2 \%$ nurses strongly agreed while 38 or $41.3 \%$ agreed that improper work environment can cause stress. Only $1 \%$ disagreed and 4 or $4.3 \%$ were satisfied about their work environment as shown in Fig. 20.

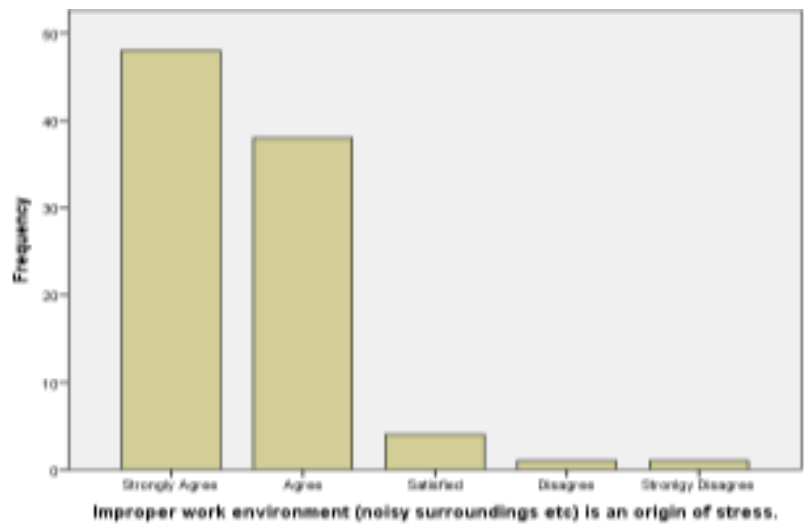

Fig. 20: Improper work environment causes stress

To question 18, that inappropriate communication between nurses and doctors causes stress, 53 or $57.6 \%$ strongly agreed and 35 or $38 \%$ agreed that it is source of stress while $1 \%$ disagreed and 3or $3.3 \%$ of nurses were satisfied. The data is presented in Fig. 21.

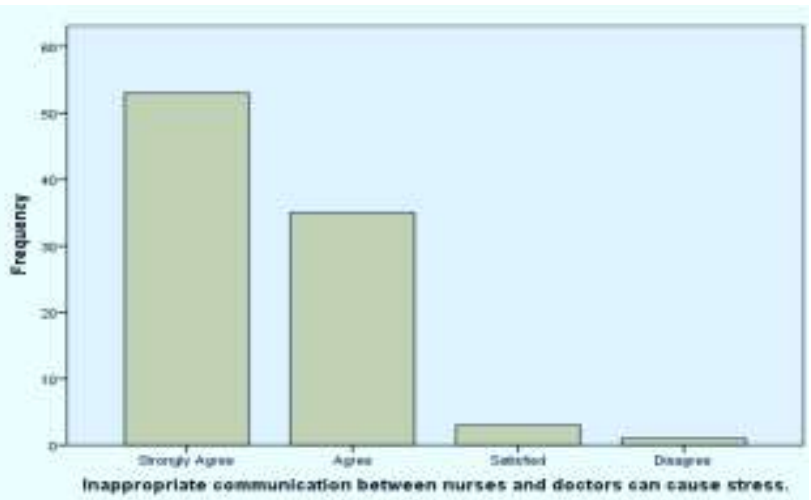

Fig. 21: Inappropriate communication between nurses and doctors causes stress

\section{Summary of Results}

According to this study, we were able to identify the major causes of stress amongst the nurses of ICU at Ittefaq Hospital, Lahore. The results have been summarized in Table 2. The responses of the nurses can be categorized into three categories; overwhelming majority (above 60\%), majority (above or close to 50\%) and moderate (close to or below 40\%).

An overwhelming majority of the nurses (78.2\%) nurses responded that prolonged shifts or extra duties causes stress to them. This is closely followed by lack of support from supervisors/managers which $68.5 \%$ nurses believed to be reason of stress. Another major reason of stress is excessive workload which was believed by $65.2 \%$ of nurses to be a cause of stress. Similarly, shortage of staff was also a major source of stress $(64 \%)$.

Major reasons of stress identified amongst nurses were inappropriate communication between nurses and doctors (57.6\%), possibility or fear of cross-infection (57.6\%), unexpected death of patients $(56.2 \%)$, shortage of staff $(54 \%)$, lack of appropriate knowledge about specialized equipment $(53.3 \%)$, patient undergoing painful procedure $(53.3 \%)$, prolonged standing and no breaks (52.2\%), improper work environment $(52.2 \%)$, lack of motivation $(51.1 \%)$, problematic or bad-mannered patients, aggressive and demanding family members $(47.8 \%)$, and conflicts with doctors during duty hours $(47.8 \%)$, .

Moderate causes of stress (strongly agreed and agree sources) can be listed as; lack of resources $46.1 \%$ (strongly agreed and agreed), lack of practice and inadequate skills (44.6\% (strongly agreed) and $42.2 \%$ (agreed)) and lack of motivation $43 \%$ (agree).

In the category of disagreed and strongly disagreed category to the causes of stress in the questionnaire less than $10 \%$ of nurses responded which means that questionnaire effectively listed the causes of stress.

A detailed summary of the results is presented in the Table 2. . 
Table 2: Frequency and percentage of items (e.g. frequency 2 and percentage $2.2 \%$ )

\begin{tabular}{|c|c|c|c|c|c|c|}
\hline S.N. & Contents & $\begin{array}{l}\text { Strongly } \\
\text { Agree }\end{array}$ & Agree & Satisfied & Disagree & $\begin{array}{l}\text { Strongly } \\
\text { Disagree }\end{array}$ \\
\hline 1. & $\begin{array}{l}\text { Lack of knowledge about operating special equipment } \\
\text { can (ventilators, etc.) cause stress. }\end{array}$ & $\begin{array}{l}49 \\
53.3 \% \\
\end{array}$ & $\begin{array}{l}32 \\
34.8 \% \\
\end{array}$ & $\begin{array}{l}4 \\
4.3 \% \\
\end{array}$ & $7.7 \%$ & NIL \\
\hline 2. & $\begin{array}{l}\text { Lack of practice and inadequate skills in performing } \\
\text { any procedure can cause stress. (ABGS sampling, etc.) }\end{array}$ & $\begin{array}{l}41 \text { or } \\
44.6 \% \\
\end{array}$ & $\begin{array}{l}39 \\
42.2 \% \\
\end{array}$ & $\begin{array}{l}6 \\
6.5 \% \\
\end{array}$ & $\begin{array}{l}6 \\
6.5 \% \\
\end{array}$ & NIL \\
\hline 3. & Excess work load is a reason of stress. & 60 & $\begin{array}{l}29 \\
31.5 \%\end{array}$ & $\begin{array}{l}3 \\
3.3 \%\end{array}$ & NIL & NIL \\
\hline 4. & Shortage of staff is a source of stress. & $\begin{array}{l}59 \\
64.1 \% \\
\end{array}$ & $\begin{array}{ll}32 \\
34.8 \% \\
\end{array}$ & $\begin{array}{l}1 \\
1.1 \% \\
\end{array}$ & $\begin{array}{l}1 \\
1.1 \% \\
\end{array}$ & NIL \\
\hline 5. & $\begin{array}{l}\text { Prolong shifts or extra duties (night duty and overtime) } \\
\text { are source of stress. }\end{array}$ & $72 \%$ & $\begin{array}{l}15 \\
16.2 \%\end{array}$ & $2.2 \%$ & $2.2 \%$ & $1.1 \%$ \\
\hline 6. & $\begin{array}{l}\text { Prolong standing and no time for break is a reason of } \\
\text { stress }\end{array}$ & $\begin{array}{l}48 \\
52.2 \%\end{array}$ & $\begin{array}{l}37 \\
40.2 \% \\
\end{array}$ & $\begin{array}{l}4 \\
4.3 \% \\
\end{array}$ & $\begin{array}{l}2 \\
2.2 \% \\
\end{array}$ & $1.1 \%$ \\
\hline 7. & $\begin{array}{l}\text { Lack of support from supervisor/manager is a source } \\
\text { of stress. }\end{array}$ & $\begin{array}{l}63 \\
68.5 \% \\
\end{array}$ & $\begin{array}{l}24 \\
26.1 \% \\
\end{array}$ & $\begin{array}{l}1 \\
1.1 \% \\
\end{array}$ & $\begin{array}{l}5 \\
5.4 \% \\
\end{array}$ & NIL \\
\hline 8. & $\begin{array}{l}\text { Lack of motivation and recognition for ones' effort is a } \\
\text { reason of stress. }\end{array}$ & $\begin{array}{l}47 \\
51.1 \%\end{array}$ & $\begin{array}{l}40 \\
43.5 \%\end{array}$ & $\begin{array}{l}4 \\
4.3 \%\end{array}$ & $\begin{array}{l}1 \\
1.1 \%\end{array}$ & NIL \\
\hline 9. & $\begin{array}{l}\text { Conflict with doctors during duty hours can cause } \\
\text { stress. }\end{array}$ & $\begin{array}{ll}36 \\
39.1 \%\end{array}$ & $\begin{array}{l}44 \\
47.8 \%\end{array}$ & $\begin{array}{l}7 \\
7.7 \%\end{array}$ & $1.1 \%$ & $\begin{array}{l}4.3 \% \\
4.3 \%\end{array}$ \\
\hline 10. & Lack of cooperation among nurses is a cause of stress. & $\begin{array}{l}46 \\
50 \% \\
\end{array}$ & $\begin{array}{l}38 \\
41 \% \\
\end{array}$ & $\begin{array}{l}4 \\
4,3 \% \\
\end{array}$ & NIL & $\begin{array}{l}4 \\
4.3 \% \\
\end{array}$ \\
\hline 11. & $\begin{array}{l}\text { Lack of resources and availability of equipment can } \\
\text { (ventilators, etc) cause stress }\end{array}$ & $\begin{array}{ll}41 \\
46.1 \% \\
\end{array}$ & $\begin{array}{l}43 \\
46.7 \% \\
\end{array}$ & $\begin{array}{l}6 \\
6.5 \% \\
\end{array}$ & $\begin{array}{l}1 \\
1.1 \% \\
\end{array}$ & NIL \\
\hline 12. & Unexpected death of patient is a cause of stress. & $\begin{array}{l}52 \\
56.2 \% \\
\end{array}$ & $\begin{array}{l}37 \\
40.2 \% \\
\end{array}$ & $\begin{array}{l}3 \\
3.3 \% \\
\end{array}$ & NIL & NIL \\
\hline 13. & $\begin{array}{l}\text { Problematic or bad-mannered behaviour of patients are } \\
\text { the reason of stress. }\end{array}$ & $\begin{array}{l}46 \\
50 \% \\
\end{array}$ & $\begin{array}{l}40 \\
43.5 \% \\
\end{array}$ & $\begin{array}{l}6 \\
6.5 \% \\
\end{array}$ & NIL & NIL \\
\hline 14 & $\begin{array}{l}\text { Aggressive and demanding family members are source } \\
\text { of stress. }\end{array}$ & $\begin{array}{l}40 \\
43.5 \% \\
\end{array}$ & $\begin{array}{l}44 \\
47.8 \% \\
\end{array}$ & $\begin{array}{l}3 \\
3.3 \% \\
\end{array}$ & $5.4 \%^{5}$ & NIL \\
\hline 15. & $\begin{array}{l}\text { Patient is undergoing through painful procedure (CVP } \\
\text { line, CPR, etc) is a reason stress. }\end{array}$ & $\begin{array}{l}35 \\
38 \% \\
\end{array}$ & $\begin{array}{l}49 \\
53.3 \% \\
\end{array}$ & $\begin{array}{l}6 \\
6.5 \% \\
\end{array}$ & $\begin{array}{ll}1 \\
1.1 \% \\
\end{array}$ & $1.1 \%$ \\
\hline 16. & $\begin{array}{l}\text { Possibility or fear of getting cross infection from } \\
\text { patients can (tuberculosis, hepatitis B, C) cause stress. }\end{array}$ & $\begin{array}{l}53 \\
57.6 \% \\
\end{array}$ & $\begin{array}{l}30 \\
32.6 \% \\
\end{array}$ & $\begin{array}{l}8 \\
8.7 \% \\
\end{array}$ & NIL & $1.1 \%$ \\
\hline 17. & $\begin{array}{l}\text { Improper work environment (noisy surroundings etc) } \\
\text { is an origin of stress. }\end{array}$ & $\begin{array}{l}48 \\
52.2 \% \\
\end{array}$ & $\begin{array}{l}38 \\
41.0 \% \\
\end{array}$ & $\begin{array}{l}4 \\
4.3 \% \\
\end{array}$ & $1.1 \%$ & $\begin{array}{l}1 \\
1.1 \% \\
\end{array}$ \\
\hline 18. & $\begin{array}{l}\text { Inappropriate communication between nurses and } \\
\text { doctors can cause stress. }\end{array}$ & $\begin{array}{l}53 \\
57.6 \% \\
\end{array}$ & $\begin{array}{l}35 \\
38.0 \% \\
\end{array}$ & $\begin{array}{l}3 \\
3.3 .2 \%\end{array}$ & $\begin{array}{l}1 \\
1.1 \% \\
\end{array}$ & NIL \\
\hline
\end{tabular}

\section{Discussion}

There is no doubt that nursing profession is one of the most stressful occupation. This is why this profession is marred with high staff nurses turnover, absenteeism and burnout. In this study, our focus was on the factors which cause stress among nurses working in Intensive Care Unit (ICU) of Ittefaq Hospital. We were able to identify that nurses suffer from stress due to various reasons based upon the responses received from the questionnaire. The results obtained from the questionnaire are compared and discussed based upon the reported literature on such surveys conducted on stress in the nurses especially in the ICUs

An overwhelming majority $78.2 \%$ of nurses responded that prolonged shifts and extra duties causes stress. We can combine this with the responses received to prolonged standing and not enough breaks to which $52 \%$ strongly agreed while $40.3 \%$ agreed as source of stress. This gives a clear indication that working hours of the ICU nurses and no rest are the prime reasons of stress. Similar results have been reported in literature as well. For example, according to a study conducted by Educational Hospital in Ahwaz, Iran, 50\% ICUs nurses suffer from stress due to prolonged shifts and prolonged duties without breaks (Shila Latifzadeh, 2015). The situation becomes clearer when we take into account the responses to the stress caused by work overload. $65.3 \%$ of nurses strongly agreed while $31.5 \%$ agreed that work overload causes stress to them. The responses obtained are in line with an earlier study which concluded that $81 \%$ of nurses suffer from stress due to work overload. The study was reported in the International Journal of Innovative Research (Khan et al., 2015).

Stress related to shortage of staff response was $64 \%$ strongly agree and $32 \%$ agreeand it is similar to study findings by Journal of Chitwan Medical College in Nepal 
that $82 \%$ ICUsnurses had stress because of shortage of staff (Mehta \& Singh, 2015).

Lack of support from supervisors and managers was another major stress causing factor amongst the nurses. $68.5 \%$ nurses strongly agreed while $26 \%$ agreed that lack of support causes them stress. Lack of support often leads to decreased motivation due to recognition of one's hard work and dedication to work from the management. It is evident from the responses received as well; $51 \%$ nurses strongly agreed while $43 \%$ agreed that lack recognition and motivation from management causes them stress. This phenomenon has been documented in other studies as well. Recently, a report published in the International Journal of Innovative Research and Development in Pakistan stated that $52 \%$ of nurses working in ICU reported frequent occurrence of stress; $32 \%$ reported extreme occurrence and $16 \%$ reported occasional occurrence of stress due to lack of support from supervisors and management(Khan et al., 2015). Another study reported $22 \%$ of nurses suffer from severe stress due to lack to support from supervisors and manager(Pawar, 2014). In addition, a study reported in International Journal of Science and Researchreported 52\% nurses face stress due to lack of support from supervisor and mangers (Gulavani \& Shinde, 2014).

Nurses spent a lot of time with patients taking care of them. They take great interest in patients' well-being. This is evident from the responses received related to patients' medical conditions. To the question about unexpected deaths of the patients, $56 \%$ nurses strongly agreed while $43 \%$ agreed that it causes them stress. These results are in line with the findings reported in the International Journal of Science and Research that 50\% nursessuffer from extreme occurrence of stress due to death and dying patients under their care (Gulavani \& Shinde, 2014). Patients undergoing painful procedures (e.g., CPR, C.V.P line) causes stress to nurses; $38 \%$ strongly agreed, $53 \%$ were agreed in their responses. These results match closely to the results reported elsewhere for example, it was reported in the Journal of Chitwan Medical College Nepal, 48\%nurses feel stressed when patients undergo painful procedure (RK Mehta \& Singh, 2015).

Despite taking care of patients with utmost dedication, nurses are supposed to pay close attention to their own wellbeing as well. There is a very high likelihood of getting an infection or disease from a patient especially if it is contagious. Special precautions need to be exercised while treating such patients. In response to getting cross-infection (hepatitis etc.) from patients, 57.6\% nurses strongly agreed while $32.7 \%$ agreed the risk causes them stress. The finding is similar to reported in literature for example, in Indian journal of Occupation and Environmental Science, 60\% nurses suffer stress due to fear of getting cross-infection (in this case hepatitis) while treating the patients in ICUs (Kane, 2009).

The importance of proper communicaiton between doctors and nurses and also amongst nurses can not be overstated. A professional relationship between doctors and fellow nurses is of utmost importance for the patients well being and proper management. Whenever there are conflicts, lack of coperation or communicaton, problems appear and cause stress. In reponse to lack of commnicaiton as reason of stress, $57.6 \%$ nurses strongly agreed while $38 \%$ agreed. Similar patterns of have been reported in literature as well, for example, a recent study published in the International Journal of Science and Research shows that 53\%, nurses reported occasional, frequent and extreme occurrence of stress due to conflict and inappropriate communication with peers and doctors (Gulavani \& Shinde, 2014). A study published in International Journal of Health and policy Management showed that $50 \%$ of nurses suffer from stress due to poor communicaiton between nurses and doctors (Mosadeghrad, 2013). In response to quesiton related to conflicts with doctors as a source of stress, $39 \%$ nurses strongly agreed while $47.8 \%$ agreed to the statement. The figures match well with a study published in the International Journal of Science and Research, which claimed that $49 \%$ of nurses working in ICUs suffer from stress due to conflicts with doctors during the duty hours (Gulavani \& Shinde, 2014).

Communication and cooperation between nurses is also very important to maintain a professional workpalce. In response to question to lack of cooperation as a source of stress, $50 \%$ nurses strongly agreed while $41 \%$ agreed that this causes stress to them. Studies published in the Journal of Chitwan Medical CollegeNepal also showed that lack of proper communication amongst nurses was identified as source of stress in $68 \%$ of nurses while $64 \%$ nurses reported stress was caused due when they are facing problems with peers and nurses (Mehta \& Singh, 2015).

Nurses working in the ICUs are expected to be fully versed with the modern life saving equipment installed there. Lack of proper training or experience can be a major source of stress and also can have severe consequences for the patients. In response to question about lack of knowledge about specialized equipment, $53.3 \%$ nurses strongly agreed while $34.8 \%$ nurses agreed it causes stress to them. These results match well with the studies reported elsewhere. For example, a study published in the Indian Journal of Occupation and Environmental Science reported 65\% nurses feel stress due to inadequate skills about operating equipment in the ICUs (Kane, 2009).

In response to lack of practice in perfoming speical procedure as soruce of stress, $44 \%$ nurses strongly agreed while $42 \%$ nurses agreed to the statement. In a study published in the Iranian Journal of Nursing and Midwifery 
Research $56 \%$ nurses reported to feel stressed due to lack of experience while working in ICUs(Adib-Hajbaghery, Khamechian, \& Alavi, 2012) which matches closely with the results obtained in the present study.

Nurses interact constantly with patients and their families. Well-mannered patients are easy to administer drugs or take vitals while problematic patients may make the job of nurses highly stressful. Same goes to the behavior of patients' family members towards nurses. In response to questions about identifying problematic or ill-mannered patients as source of stress, 50\% nurses strongly agreed while $43.5 \%$ nurses agreed to the statement. The results of current study match closely with another study published in the International Journal of Innovative Research and Development in Pakistanwhich states that $81 \%$ nurses reported to develop stress due to problematic patients and their family members (Khan et al., 2015). In response to question about aggressive and demanding family members as source of stress, $43 \%$ nurses strongly agreed while $47 \%$ agreed to the statement. In a study published in the Journal of Chitwan Medical College (JCMC), Nepal it was claimed that $70 \%$ nurses developed stress while attending to highly demanding patients. In the same study $48 \%$ of nurses said to develop stress due to abusive or aggressive family members of patients (RK Mehta \& Singh, 2015).

Work environment influences a person's mood and stress level and nurses are no different. ICU nurses are always working under high stress conditions and improper work conditions like noisy surroundings etc. may contribute to such situations. In response to question about improper work environment as a source of stress $52.7 \%$ nurses strongly agreed while $38 \%$ agreed such conditions causes stress to them. The findings match closely to the ones published in KMJ where authors reported that $67 \%$ nurses reported to develop stress due to improper work environment(Shamaila Khalid, 2012). Similarly, in a study published in the Iranian journal of Nursing and Midwifery Research, the authors reported improper working environment was identified as a cause of stressin $73 \%$ of the nurses in their study which matches with the results of the findings of our study (Adib-Hajbaghery et al., 2012).

It is worth noting here that the trends observed in the current study on the stress conditions of nurses working in the ICUs of Ittefaq Hospital match closely with the trends observed in the literature. Thus, it is safe to say our study objectively identified the various causes of stress in nurses.

\section{Conclusions and Recommendations}

\section{Conclusions}

The study is aimed at identifying the causes of stress amongst daily routine of nurses working in the ICU unit of Ittefaq Hospital Lahore. A questionnaire was developed and distributed to gain an insight into factors which may be causing stress to the nurses. The results were analyzed using statistical tools. An overall finding of the study is that all the nurses were suffering from stress however, the reasons of stress are different. Consensus was that three biggest causes of stress are prolonged shifts and extra duties, shortage of staff and excessive workload.

The other major causes of stress identified are inappropriate or poor communication between doctors and nurses, lack of support and motivation, unexpected deaths or patients undergoing painful procedures, lack of breaks, lack of cooperation from peers and supervisors/managers. The patients themselves can also be a source of stress for example, problematic patients or their aggressive family members as well as improper work environment also contribute to stress.

The data obtained from the study were compared to the studies published in literature. The data obtained matches well with the published results which helps us to ascertain that the causes identified are valid and hold data processing standards.

In a nutshell, it can be concluded that nurses working in the ICU of Ittefaq hospital are working under highly stressful working conditions. Efforts should be made to eliminate the causes of stress through proper management and therapy techniques.

\section{Limitations}

Everyone perceives stress differently as there is no definite definition of stress. Thus sometimes it can be challenging to interpret such data.

In such situations, proper use of statistical tools becomes very important. Data gathering, analyzing and interpreting of data on a software tool such was SPSS was a big challenge.

Time was the one of the major limitation in the study. If the projects were defined in advance at the very beginning of semester, it is expected we would have been able to get much better results as the study could have been extended to a much larger sample size.

Finance was also one the limitations because there was no financial support available for any of the research work. All expenditures were borne by the research students themselves.

Such surveys are not conducted very often in our work environment, thus acceptance towards such surveys is low in the society. Some nurses were reluctant to cooperate. Similarly, gathering data was also a challenge as staff nurses had duties in various shifts and being in the ICU staff were very busy in attending the patients. 
Overall, it was a very good learning exercise, I learned a great deal about doing practical research, learnt to use various tools and interpretation of data.

\section{Recommendations}

Based on the results obtained from the research study, we would like to recommend the implementation of stress alleviating programs organized by the hospital management and policy makers.

The biggest stress causing factors are found to be related to the prolonged shits, extra duties, and lack of breaks. Such factors can be addressed by proper management of schedule assignment of nurses. The hospital managements must implement a limit to the maximum allowable working shift for a nurse which should not excess 12 hours in one go.

Hospitals should also hire enough staff to address the issue of staff shortages. The management should also implement proper break schedules for nurses and nurses should be made to comply with such schedules.

The policy makers and management should introduce management skills courses and workshops for Nursing supervisors and managers to improve the communication skills. Similar courses should be arranged for nurses as well. At the management level counselling session should be arranged for nurses.

Rewards and appreciation should be given to nurses according to work performance to provide incentive to the nurses and increase motivation levels.

The hospital managements should arrange recreational activities for the staff nurses which not only help to reduce stress but also provide chance to improve communication between the nurses and the management.

Stress intervention programme should be introduced in nursing schools and colleges. Similarly, nursing supervisors and managersshould be encourage the nurses to participate in stress reducing or relaxation therapies. Such therapies could be breathing exercises, social support therapies, mediation etc.

The introduction of such programs could help in coping stress and help reduce positive stress while building positive stress at the same time. Positive stress will motivate the nurses and build confidence while increasing job satisfaction and performance at the same time.

\section{References}

Adib-Hajbaghery M, Khamechian M and Alavi NM (2012) Nurses' perception of occupational stress and its influencing factors: A qualitative study. Iranian journal of nursing and midwifery research 17(5): 352.

Cavalheiro AM, Moura Junior DF and Lopes AC (2008) Stress in nurses working in intensive care units.
Revista Latino-Americana de Enfermagem 16(1): 29-35.

Chauhan N (2014) Nursing in Pakistan: Handle with care the express

Ellen S (2012) Slovin's Formula Sampling Techniques

French SE, Lenton R, Walters V and Eyles J (2000) An empirical evaluation of an expanded nursing stress scale. Journal of nursing measurement 8(2): 161178.

Kato T (2014) Coping with interpersonal stress and psychological distress at work: comparison of hospital nursing staff and salespeople. Psychology research and behavior management 7: 31 .

Khamisa N, Oldenburg B, Peltzer K and Ilic D (2015) Work Related Stress, Burnout, Job Satisfaction and General Health of Nurses. International journal of environmental research and public health 12(1): 652-666.

Khan N, Anwar H and Sayed M (2015) Prevalence of Stress Factors in Nurses in Leady Reading Hospital (LRH), Khyber Teaching Hospital (KTH) and Hayatabad Medical Complex (HMC) Hospitals, Peshawar, KPK. International Journal of Innovative Research and Development 4(4).

McDonagh ML (2014) Nurse Unions Continue to Push for Nurse-Patient Ratio Legislation. Retrieved from: http://wwwlittlercom/healthcare-employmentcounsel/nurse-unions-continue-push-nurse-patientratio-legislation health care employment counsel

McGrath A, Reid N and Boore J (2003) Occupational stress in nursing. International journal of nursing studies 40(5): 555-565.

Mehta R and Chaudhary R (2005) Job related stress among the nurses working in critical care areas at BPKIHS, Nepal. Nursing and Midwifery Research 1(2).

Mehta R and Singh I (2015) Stress among nurses working in critical care areas at a tertiary care teaching hospital. Nepal Journal of Chitwan Medical College 4(4): 42-48.

Milutinović D, Golubović B, Brkić N and Prokeš B (2012) Professional stress and health among critical care nurses in Serbia. Archives of Industrial Hygiene and Toxicology 63(2): 171-180.

Mosadeghrad AM (2013) Occupational stress and turnover intention: implications for nursing management. International journal of health policy and management 1(2): 169.

Nizami A, Rafique I, Aslam, F, Minhas FA and Najam N (2006) Occupational stress and job satisfaction 
among nurses at a tertiary care hospital. Journal of Pakistan Psychiatric Society 3(1): 25-29.

Pawar MMN (2014) Level of stress among the nurses working in Intensive care units

Ramezanli S, Kashkaki AR, Talebizadeh M and Jahromi MK (2015) A Study of the Coping Strategies Used by Nurses Working in the Intensive Care Units of Hospitals Affiliated to Jahrom University of Medical Sciences. Int J Curr Microbiol App Sci 4(4): 157-163
Shamaila Khalid U I, Salma Sheikh, Mahvish Faisal (2012) Frequency of stress and depression in female. KMJ 2(1): 10-14.

Shila Latifzadeh KZ (2015) Occupational Stress and Its Related Factors in Nurses Working in Intensive Care Units of Educational Hospitals. Journal of Novel Applied Sciences 483-487.

Zakerian SA, Rahmani A, Abbasinia M , Dehghan SF , Ahmadnezhad I, Asghari M. (2014). A survey of the relation between workload and quality of life among hospital. Pakistan journal of public health 4(1): 6-7. 